\title{
Effects of Performance on Mechanical properties of Sawdust/Carbon Fibre Reinforced Polymer matrix Hybrid Composites
}

\author{
M. ASHOK KUMAR, T. MARUTHI CHOWDARY, \\ K. CHANDRA SEKHAR BALAJI, E. DHANUNJAYA GOUD, S. NAGARAJU, \\ K. SHAIK AHMMED, B. RAJA SEKHAR \\ Department of Mechanical Engineering, Dr KV Subba Reddy Institute of Technology-Dupadu- \\ Village, Kurnool-518218, Andhra Pradesh, India \\ E-mail address: ashokkumarmala7@gmail.com
} Keywords: effects of Performance; Mechanical properties; Fibre Reinforced; Polymer matrix
Hybrid Composites

\begin{abstract}
Short carbon fibre (CF) and sawdust (SD) were dispersed in to the epoxy (EP) matrix in order to manufacture polymer hybrid composites using compression moulding technique. The mechanical properties of flexural properties of hybrid, compression moulded, chopped $\mathrm{CF} / \mathrm{SD} /$ epoxy composites have been investigated taking into account the effect of hybridization by these two fillers. Hybridization with small amounts of SD makes these CF composites more suitable for technical applications. The simultaneous compounding of epoxy with two fillers was done to obtain a hybrid composite. This system is expected to have considerable mechanical properties, good surface finish and low cost. It has been found that the tensile properties of filled epoxy were higher than unfilled epoxy. By incorporating up to 30\% (by mass) Carbon fiber (CF) and 10\% sawdust (SD) namely $\mathrm{S}_{3}$ sample flexural strength was increased by $12.5 \%$. Thus it is shown that the durability of CF/SD filled epoxy composites can be enhanced by hybridization with small amount of CF. The hybrid effects of the flexural strength and modulus were studied by the rule of hybrid mixture.
\end{abstract}

\section{INTRODUCTION}

Epoxy resin is versatile and widely accepted matrix material for the fabrication of advanced composites are used in hardware components, electronic circuit board materials, rodomes and missile equipment components because of its excellent bonding, physico-chemical, thermal, mechanical, dielectrical and aging characteristics[1-4]. In the last two decades, developments in the field of natural fiber-polymeric composites have grown from laboratory scale of fundamental research to industrial implementation. The renewed interest of natural fibres over their synthetic fiber counter part is that they are abundant in nature and also they are renewable materials. Owing to their low specific gravity as compared to synthetic fibres are able to provide a high strength to weight ratio in plastic materials. The usage of natural fibres also provides healthier working conditions than the synthetic fibres. Besides the less abrasive nature of the natural fibres, when compared to that of the synthetic fibres offers the friendlier processing environment as the wear off the tools could not be reduced. Furthermore, natural fibres offers good thermal and insulating properties and these are easily recyclable and biodegradable. These advantages have been gained interest in the Automobile industry where materials of light weight, higher strength to weight ratio, and minimum environmental impact are required. Natural fibres like jute sisal, jute, coir, banana etc. have gained substantial importance as reinforcements in polymer matrix composites. A lot of work has been done by many researchers on the composites based on these fibres [5-8]. Despite the attractive of natural fibre reinforced polymer matrix composites. They are suffer from the lower modulus, lower strength and relatively poor moisture resistance compared to synthetic fiber reinforcement composites such as glass and carbon fibre reinforced plastics. Natural fibre reinforced polymer matrix composites are very sensitive to influences from environmental agents such as water. Data on the effect of moisture on retention of mechanical properties of natural fiber 
reinforced composites during long term service are crucial for them to be utilised in outdoor applications. Weakness of the natural fibers composites can be improved by pre-treatment of the natural fibers using physical, chemical to improve interaction between fiber and matrix. Mechanical properties of fiber reinforced composites are greatly influenced by adhesion characteristics of fiber matrix interface. It is shown by previous studies that moisture causes degradation of mechanical properties of natural fiber reinforced composites to a larger extent when compared to synthetic fiber reinforced composites, as consequence of higher moisture sorption behaviour, and the organic nature of the of the natural fibres. It is necessary to enhance the hydrophobisity of the natural fibres by chemical treatments with suitable coupling agent or by coating with appropriate resin in order to develop composites with better mechanical properties and environmental performance. Hybridization of natural fibers with stronger and more corrosion resistance synthetic fiber, for example, glass or carbon fiber, can also improve the stiffness, strength as well as a moisture resistance of the composite. Using a composite that contains the two or more different types of fibers, the advantage of one fiber could complement the lacking in other. As a consequence, a balance in performance and cost could be achieved through proper material design. However, only few studies on mechanical properties of natural and synthetic fibres reinforced polymer matrix hybrid composites are available to date but sawdust/carbon fibre reinforced hybrid composites are not available. Incorporating filler particles into the matrix of fiber reinforced composites, synergistic effects may be achieved in the form of higher modulus and reduced material cost, and yet a accompanied with decreased strength and impact toughness. To improve its working performance further, use in advanced engineering applications toughening of epoxy is essential. By improving its flexural and impact strength it is made useful for the development of materials with high performance characteristics. The toughness of epoxy has been increased by adding fibres/filler/mineral materials [9-32]. In this work, the behaviour of composites and hybrid composites of sawdust and carbon fiber filled epoxy matrix under flexural, thermal, and morphological properties were studied.

\section{MATERIALS AND METHODS}

Carbon fibres, type T700S ${ }^{\circledR}$ was obtained from Toray Industries, Inc., Tokyo, Japan. Sawdust was obtained from Sree composites, Hyderabad; particle size was in between 100-120 microns. The epoxy (Araldite-LY 556 and Amine Hardener- HY 951) employed in this study was Ciba-Geigy of India Limited. In addition, the glass fibre (density: $350 \mathrm{~g} / \mathrm{m}^{2}$ ) was supplied by Saint Gobain Industries Ltd., Bangalore, India.

The composite was prepared by hand layup technique by rule of hybrid mixtures. Firstly, glass moulds were prepared based on ASTM standards with15 x $15 \times 3 \mathrm{~cm}^{3}$. Then sawdust was kept in the oven for half an hour to remove moisture. Then mould surfaces were sprayed with polyvinylalcohol in order to retain the shape of the casting after it is being cured while it is being taken out from the oven. A layer of modified epoxy was poured into the mould upon which CF was stacked randomly by parts [2]. Then the SD was mixed well with epoxy using mechanical stirrer until it mixture left with no air bubbles. Care was taken to keep the mould flat using spirit level while mixture is being poured. Once the mixture poured completely in to the mould then thin OHP sheet was spread over gently to keep the mould under subjected compression and this also facilitates to keep the dust particle at bay. Then the mould kept aside for 24hours curing, then it is taken into the oven to make sure to melt the mould releasing agent ought to be melt properly. Then the casting should be taken out from the mould using spatula and knife. Then the composites were cut in to ASTM sizes for testing. Flexural (bending) specimens were cut on par with ASTM D 53455. Flexural tests were performed on Instron universal testing machine (3369). The cross head speed was maintained 50 $\mathrm{mm} / \mathrm{min}$. All the tests were accomplished at a room temperature of $23^{\circ} \mathrm{C}$. At least, 5 samples were tested for each composition and results were averaged. Scanning electron microscopy (SEM) studies of the fractured surface of the tensile specimen were carried out on a Joel (6380LA, Japan). The specimen was sputter-coated with gold to increase surface conductivity. The thermal characteristics TGA, DSC measured on polymer composites using SDT Q600 TGA/DSC (TA 
Instruments) at a rate of $10^{\circ} \mathrm{C} / \mathrm{min}$ under nitrogen flow measurements were carried out at $20^{\circ} \mathrm{C}$ temperature, $40 \%$ relative humidity.

\section{RESULTS AND DISCUSSIONS}

Fig.1 shows the flexural strength and modulus properties of SD/CF/EP hybrid composites as a function of filler and fiber using rule of hybrid mixtures were studied. Nearly six samples were tested and mean values are tabulated in the Table1 and figure1. Sample $\mathrm{S}_{3}$ got significant results than the other samples and the reasons are attributed that addition of CF/SD would made stiffer and same are optimised at that loading as well. Furthermore more addition of SD makes the composites highly viscous and it cannot unable to flow all sides, this might be the reason for samples $\mathrm{S}_{4}$ and $\mathrm{S}_{5}$. And the reason for improved performance was epoxy molecules grafted on the surface of filler particles. The grafted fiber molecules played a role of tie molecules between the reinforcing particles and epoxy matrix. Flexural strength was increased with increase in CF content up to $30 \%$ (by mass), whereas on other hand, decreases when SD content increases, the reason is increase in SD content obviously make mixture makes difficult to flow as mentioned earlier same was observed by the authors[23,26]. Same results were observed even at for modulus. Flexural strength for $\mathrm{S}_{3}$ was increased but sudden drop was observed for $\mathrm{S}_{4}$, then it got pick up from there on but performance was still less to $\mathrm{S}_{3}$ sample.

Fig. 2 shows the differential scanning calerometry results of various samples of $\mathrm{S}_{3}, \mathrm{~S}_{4}, \mathrm{~S}_{5}$ of $\mathrm{SD} / \mathrm{CF}$ epoxy hybrid composites as a function of temperature. It was observed from the graphs that $\mathrm{S}_{3}$ sample got significantly improved the thermal stability than the $\mathrm{S}_{4}$ and $\mathrm{S}_{5}$ and the reasons attributes that due to $40 \%$ of carbon fiber which has more resistance to resist temperature and also sample $\mathrm{S}_{4}$ would got $20 \%$ of $\mathrm{CF}$ has the substantial reason for slightly decreasing thermal stability, furthermore $\mathrm{S}_{5}$ sample was also got reduced still. Overall, $\mathrm{S}_{3}$ performed without losing its weight until $352^{\circ} \mathrm{C}$, then its starts reducing gradually, whereas for $\mathrm{S}_{4}$ it got lost its weight at $350^{\circ} \mathrm{C}$ for $\mathrm{S}_{5}$ weight stated losing $349^{\circ} \mathrm{C}$, therefore $\mathrm{S}_{3}$ got higher thermal stability. Ashok kumar et al. was observed that the inorganic particle would make the composite more resistance to thermal variation. Sreenivasulu et al. were observed the same phenomenon.

SEM analysis of $\mathrm{S}_{1}, \mathrm{~S}_{2}$ and $\mathrm{S}_{3}$ samples were shown in the fig.3. SEM images of fracture surfaces of hybrid composites of $\mathrm{S}_{1}(\mathrm{EP}), \mathrm{S}_{2}(\mathrm{EP}+\mathrm{SD}), \mathrm{S}_{3}(\mathrm{EP}+\mathrm{SD}+\mathrm{CF})$ hybrid composites after flexural tests were evaluated. $S_{1}$ resembles like brittle nature as it is not filled with any stuff, thus it might have got less strength, and also sample $S_{2}$ was slightly different from the sample $S_{1}$, therefore $S_{2}$ sample was transformed from brittle to ductile nature. $S_{3}$ specimen was significantly transformed in to ductile nature and moreover interface between the fiber matrixes was good as well and it was also observed that there were no voids later, this might be the reason for improved performance. Same observations were observed by the authors [25]. 
Table: 1 Different composition of samples with varying proportions of matrix, fiber and filler contents.

\begin{tabular}{llll}
\hline Sample & $\begin{array}{l}\text { EP } \\
(\mathbf{w t} \%)\end{array}$ & $\mathbf{C F}(\mathbf{w t} \%)$ & SD(wt\%) \\
$\mathrm{S}_{1}$ & 100 & 0 & 0 \\
$\mathrm{~S}_{2}$ & 60 & 40 & 0 \\
$\mathrm{~S}_{3}$ & 60 & 30 & 10 \\
$\mathrm{~S}_{4}$ & 60 & 20 & 20 \\
$\mathrm{~S}_{5}$ & 60 & 10 & 30 \\
$\mathrm{~S}_{6}$ & 60 & 0 & 40 \\
\hline
\end{tabular}

Table: 2 Flexural properties of EP/CF/SD hybrid composites.

\begin{tabular}{lll}
\hline Sample & $\begin{array}{l}\text { Flexural } \\
\text { strength } \\
\text { (MPa) }\end{array}$ & $\begin{array}{l}\text { Flexural } \\
\text { modulus } \\
\text { (GPa) }\end{array}$ \\
\hline $\mathrm{S}_{1}$ & 54.120 & 1.244 \\
$\mathrm{~S}_{2}$ & 57.765 & 1.345 \\
$\mathrm{~S}_{3}$ & 87.066 & 1.787 \\
$\mathrm{~S}_{4}$ & 65.544 & 1.464 \\
$\mathrm{~S}_{5}$ & 54.876 & 1.567 \\
$\mathrm{~S}_{6}$ & 60.233 & 1.653 \\
\hline
\end{tabular}




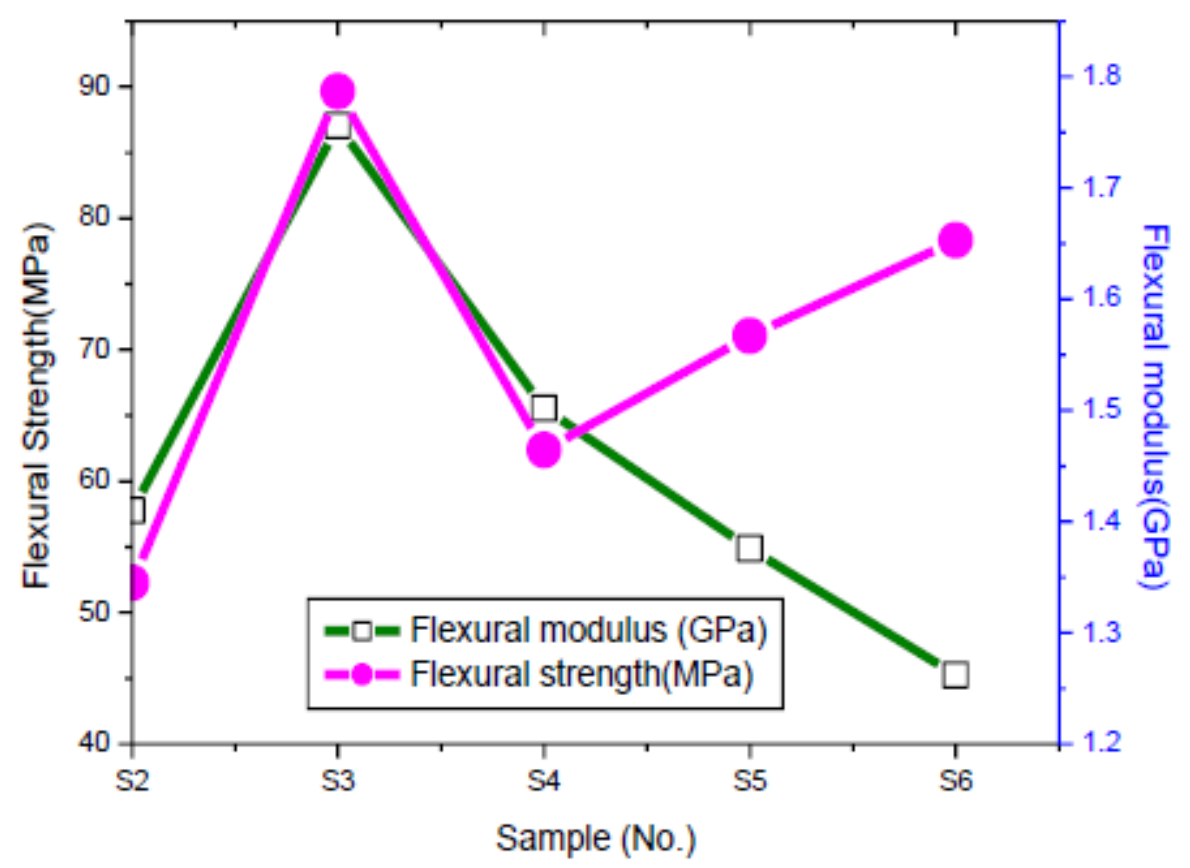

Fig.1. Flxural strength and modulus properties of SD/CF/EP hybrid composites as a function of SD \& CF.

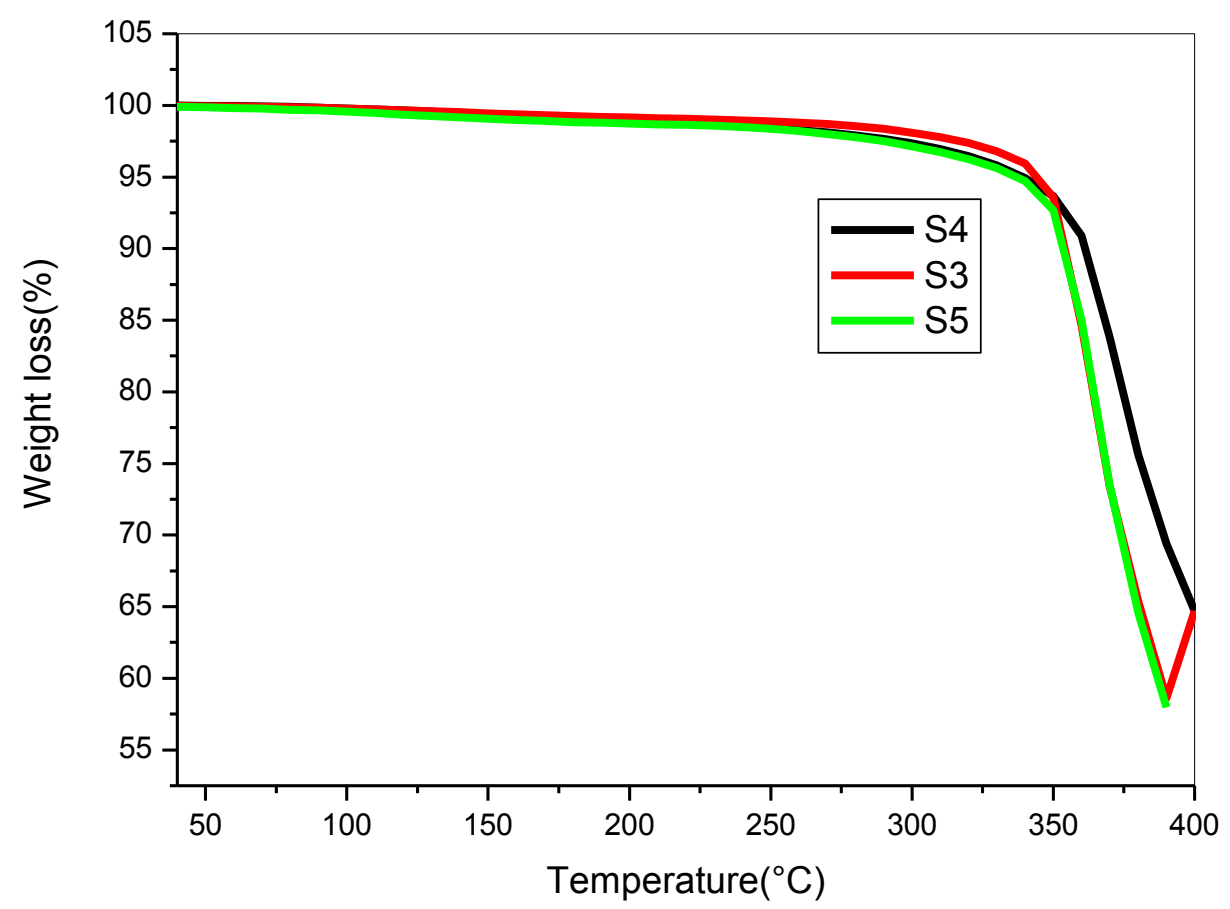

Fig.2 Thermo-gravimetric analysis of SD/CF/EP hybrid composites as a function of SD \& CF. 

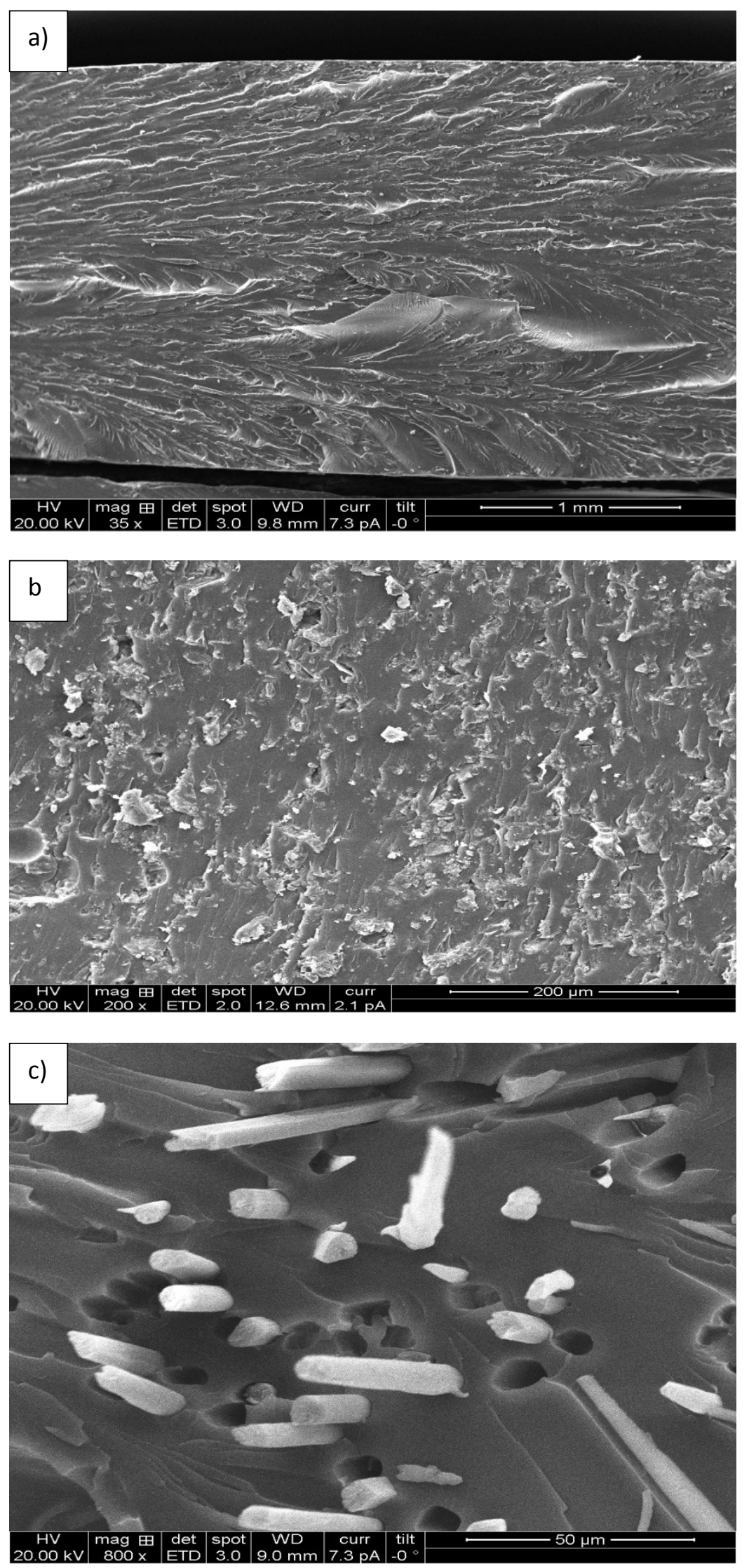

Fig.3: SEM analysis of sample (a) S1 ; (b) S3 and (s6) of SD/CF/EP hybrid composites. 


\section{CONCLUSIONS}

Our results from epoxy hybrid composites filled with CF/SD with different \% ( by mass) allow with relevant conclusions towards understanding of the behaviour polymer hybrid composites. Composite filled with both sawdust and carbon fibres were shown good mechanical and thermal properties than they filled them with differently. All of these results indicate that the $\mathrm{SD} / \mathrm{CF}$ epoxy composites might have promising automotive and aerospace applications. Thermal stability was increased up to $3^{\circ} \mathrm{C}$ for $\mathrm{S} 3$, whereas for $\mathrm{s} 4$ and $\mathrm{S} 5$ were slightly reduced due to the variation-ally decreasing of $\mathrm{CF}$ content was the significant reason.

\section{Acknowledgements}

This project is financially supported by all under graduated B.Tech students of batch (2011-15) of Dr. K.V.Subba Reddy Institute of Technology-Dupadu, Kurnool-Andhra Pradesh, India. We would like to thank our Mechanical Department Professor, Dr. M.Ashok Kumar for guiding throughout this project.

\section{References}

[1] ASTM D 543-87. Standard methods for evaluating the resistance of plastics to chemical reagents. Annual book of ASTM standards, 8(1). Philadelphia (PA): American Society for Testing and Materials; 1992.

[2] ASTM D 2734-94. Standard methods for void content of reinforced plastics. Annual book of ASTM standards, 8(2). Philadelphia (PA): American Society for Testing and Materials; 1997

[3] ASTM D 3039/D 3039M. Standard test method for tensile properties of polymer matrix composite materials. Annual book of ASTM standards, 8(1). Philadelphia (PA): American Society for Testing and Materials; 1997.

[4] Chua PS, Dai SR, Piggot MR. Mechanical properties of the glass fibre-polyester interphase Part II effect of water bonding. J Mater Sci 1992; 27:919-24.

[5] Mohan R, Kishore. Jute-glass sandwich composites. J Reinf Plast Compos 1985; 4(2):18694.

[6] De Albuquerque AC, Joseph Kuruvilla, Hecker de Carvalho Laura, Almeida Jose Roberto Morais d'. Effect of wettability and ageing conditions on the physical and mechanical properties of uniaxially oriented jute-roving-reinforced polyester composites. Compos Sci Technol 2000; 60(6):833-44.

[7] Mariatti J. Preliminary studies of woven thermoplastic composites. MSc thesis, Universiti Sains Malaysia.

[8] Park R, Jang J. Stacking sequence effect of aramid-UHMPE hybrid composites by flexural test method. Polym Test 1997; 16(6):549-62.

[9] Thwe M M, Liao K. Durability of bamboo-glass fiber reinforced polymer matrix hybrid composites. Compos Sci Technol 2003; 63:375-87.

[10] Sreenivasulu S, Vijayakumar Reddy K, Varada Rajulu A, Ramachandra Reddy. Chemical resistance and tensile properties of short bamboo fiber reinforced epoxy/polycarbonate composites. Bull Pure Appl Sci 2006; 25C:137-42.

[11] John K, Venkata Naidu S. Chemical resistance of sisal/glass reinforced unsaturated polyester hybrid composites. J Reinf Plast Compos 2007; 26:373-6.

[12] Raghu K, Noorunnisa Khanam P, Venkata Naidu S. Chemical resistance studies of silk/sisal fiber-reinforced unsaturated polyester-based hybrid composites. J Reinf Plast Compos 2010; 29(3):343-5. 
[13] Guduri BR, Varada Rajulu A, Luyt. Chemical resistance, void contents and morphological properties of hildegardia fabric/poly carbonate-toughened epoxy composites. J Appl Polym Sci 2007; 106:3945-51.

[14] Idicula Maries, Neelakantan NR, Zachariah Oammen, Thomas Sabu. A study of the mechanical properties of randomly oriented short banana and sisal hybrid fibre reinforced polyester composites. J Appl Polym Sci 2005;96:1699-709.

[15] Idicula Maries, Joseph Kuruvilla, Thomas Sabu. Mechanical performance of short banana/sisal hybrid fiber reinforced polyester composites. J Reinf Plast Compos 2010;29(1):12-28.

[16] Khalil HPS Abdul, Kang CW, Khairul A, Ridzuan R, Adawi TO. The effect of different laminations on mechanical and physical properties of hybrid composites. J Reinf Plast Compos 2009; 28:1123-8.

[17] Sreekala MS, George J, Kumaran MG, Thomas S. The mechanical performance of hybrid phenol-formaldehyde based composites reinforced with glass and oil palm fibres. Compos Sci Technol 2002; 62:339-53.

[18] Zweben C. Tensile strength of hybrid composites. J Mater Sci 1977; 12: 1325-37.

[19] Acosta JL, Morales E, Ojeda MC, Linares A. Effect of addition of sepiolite on the mechanical properties of glass fiber reinforced polypropylene. Angew Makromol Chem 1986; 138:10310.

[20] Hargarter N, Friedrich K, Catsman P. Mechanical properties of glass fiber/talc/polybutyleneterephtalate composites as processed by the radlite technique. Compos Sci Technol 1993; 46:229-44.

[21] Fu S-Y, Lauke B. Fracture resistance of unfilled and calciteparticle- filled ABS composites reinforced by short glass fibers (SGF) under impact load. Composites: Part A 1998; 29:63141.

[22] K.Prabhakar, .M. Ashok Kumar, E.V.Subbareddy, S.Kasimvali, Design And Development Of Fixture With Cantilever Beam For Inter Mediate Gear Box International Journal of Computer Technology \& Applications,4 (6),892-896.

[23] A. Kishore, D.B.Venkatesh, M.Ashok Kumar, A.Ramesh, K.Nikhil Murthy, N.Karthikeyan, Hydrophilic Modified clay Nanocomposites: Effect of clay on Thermal and Vibrational Properties, International Letters of Chemistry, Physics and Astronomy, 8:73-86, 2014.

[24] R. Sreeenivasulu, S. Madhusudhan, M. Ashok Kumar, V. Nikil Murthy, N. Kartikeyan, Synthesis and Characterization of Polymer Nanocomposites Filled with Nanoclay/Aerosil on Mechanical and Thermal Properties, International Journal of Nanomaterials and Biostructures.2013xx:xxx-xxx.

[25] Palla Hari Sankar, Y. V. Mohana Reddy, K. Hemachandra Reddy, M. Ashok Kumar, A. Ramesh, The Effect of Fiber Length on Tensile Properties of Polyester Resin Composites Reinforced by the Fibers of Sansevieria trifasciata, International Letters of Natural Sciences, 3 (2014) 7-13.

[26] M.Ashok Kumar, G.Ramachandra Reddy, A.Ramesh, BH. Nanjunda Reddy, K.R. Vishnu Mahesh, P.V. Sanjeev Kumar, Performance of coconut shell particulate filled polyester composites, Pakistan Journal of Scientific Industrial Research Ser-A, Phy. Sci, 2012, 55(3):142-148.

[27] T.Ranjeth Kumar Reddy, T.Subba Rao, R.Padma Suvarna, M.Ashok Kumar, Studies On Thermal Characteristics Of Cow Dung Powder Filled Glass -Polyester Hybrid Composites, Advances In Polymer Science And Technology: An International Journal, 2013; 3(1) : 19-21. 
[28] P.V. Sanjeev Kumar, M. Ashok Kumar, B. Chandramohan Reddy, G. Ramachandra Reddy, Compression And Impact Properties Of Clay /Epoxy Nanocomposites Reinforced With Short Weave Glass Fiber Reel, International Journal Of Nanomaterials And Biostructures, 2012; 2(3) $50-54$.

[29] M. Ashok Kumar, G. Ramachandra Reddy, G.Harinatha Reddy, K.V.P.Chakradhar, Bh. Nanjunda Reddy, N.Subbarami Reddy, Mechanical Properties Of Randomly Oriented Short Sansevieria Trifasciata Fibre/Epoxy Composites, International Journal Of Fiber And Textile Research, 2011; 1(1): 6-10.

[30] G. Ramachandra Reddy, M. Ashok Kumar, N. Karthikeyan, and S. Mahaboob Basha, Tamarind fruit Fiber (Tf) and Glass Fiber Reinforced Polyester Composites, Mechanics of Advanced Materials and Structures,, Id: 862330 (UMCM-2011-0073.R1) (accepted on 2014)( in press).

[31] D. Madhava Reddy, C.H.Rakesh, N.Karthikeyan, M.Ashok Kumar, G.Nagaraju, Utilization Of Wollastonite/ Quasi Isotropic S2 Glass Fiber Doped In To Epoxy On Mechanical And Thermal Properties, International Letters of Chemistry, Physics and Astronomy, 19(2) (2014) 191-197.

[32] G. Ramachandra Reddy, M. Ashok Kumar' A.Ramesh, Mehaboob Basha, N.Karthikeyan, K.Madhava Reddy, Preparation of Glass Fibre/ Wollastonite Reinforced Epoxy Hybrid Composite: Mechanical Properties, Pakistan Journal of Scientific Industrial Research, Ser. A: Phys. Sci., 58, 2015, 58 (1) 26-33. 